\title{
EFFECT OF THE LOCAL WALL COOLING/HEATING ON THE HYPERSONIC BOUNDARY LAYER STABILITY AND TRANSITION
}

\section{A. Sidorenko, Yu. Gromyko, D. Bountin, P. Polivanov, and A. Maslov}

Khristianovich Institute of Theoretical and Applied Mechanics Siberian Branch of the Russian Academy of Sciences 4/1 Institutskaya Str., Novosibirsk 630000, Russia

\begin{abstract}
Hypersonic boundary layer stability and transition were studied experimentally and numerically for the test case of 7 degree half-angle cone equipped with local wall heating and cooling. The experiments were performed for $M=6$. Heat flux distributions and wall pressure pulsations were measured. It was obtained that variation of the wall temperature significantly affects the transition location. It was found that development of the second mode depends on the upstream wall temperature. The results of numerical simulation confirmed the general trends of the second mode evolution obtained in the experiment.
\end{abstract}

\section{INTRODUCTION}

The development of secure and reusable reentry vehicle requires the complete control of the heat distribution on its thermal protection system (TPS). During the most critical reentry phase, the hypersonic flow along the vehicle initiates a laminar boundary layer inside of which most of the transfer phenomena take place (heat, momentum, and mass transfer). After transition to turbulence occurs, the TPS receives a sharp increase of the incoming heat flux (minimum 3 times higher). Such increase of heat fluxes can lead to a destruction of a vehicle and it is necessary to protect it adequately against this overheat. Therefore, aerospace designer needs to receive the proper information and tools allowing better prediction and, ultimately, better control of the transition at hypersonic speed.

This is an Open Access article distributed under the terms of the Creative Commons Attribution License 4.0, which permits unrestricted use, distribution, and reproduction in any medium, provided the original work is properly cited. 
For configurations having aerodynamically smooth surfaces, the transition is associated with excitation and downstream amplification of unstable boundary layer modes, namely, the first and second modes [1-4]. Although features of these instabilities and opportunities of their control have been studied by the research community for more than 50 years, they have been focused on boundary layers having fairly uniform distributions of the wall temperature and heat fluxes [4-7] or uniform heating/cooling of the model wall [8-12]. However, actual TPS may have elements of different heat conductivity and/or emissivity. Junctures between these elements lead to jumps of the heat-transfer boundary conditions. Furthermore, active TPS may produce regions of localized relative heating or cooling of the aerodynamic surface. These thermal nonuniformities may significantly affect the boundary-layer mean flow, excitation, and evolution of unstable modes and, ultimately, transition locus. Investigation of physical mechanisms associated with the foregoing thermal effects will help to design advanced TPS providing capabilities of transition control. The only work devoted to the influence of localized heating/cooling on hypersonic boundary layer stability is computational data [13].

An effect of local cooling/heating on the development of the boundary layer disturbances was studied numerically and experimentally in framework of FP7 project TransHyBeriAN for the test case of the hypersonic flow formed above the 7 degree half-angle cone under zero angle of attack.

\section{WIND TUNNEL EXPERIMENTS}

\subsection{Experimental Setup}

The supersonic wind tunnel "Tranzit-M" is a short duration aerodynamic facility with range of Mach number $M=4-8$ and high values of Reynolds number [14]. Scheme of the wind tunnel is presented in Fig. 1. Initially, the air is accumulated in the first prechamber and volumes of the ohmic heaters where after heating, it acquires high temperature and pressure. After opening the high-speed valve, the gas has been throttling into the second prechamber and afterwards, it is flowing into the test section through the contoured nozzle. Runtime of the wind tunnel is limited by the volume of the vacuum tank $\left(6.5 \mathrm{~m}^{3}\right)$ and approximately equal to $110-200 \mathrm{~ms}$ for $\mathrm{M}=6$. The wind tunnel is equipped with pressure and temperature sensors in the first and second prechambers. The diameter of the contoured nozzle is $300 \mathrm{~mm}$.

The experiments were carried out at $\mathrm{M}=6$, stagnation temperature $T_{0}$ $=370 \mathrm{~K}$, and stagnation pressure $P_{0}=3.8-12$ bar. Reynolds number was varied in a range of $\mathrm{Re}_{1}=(4-20) \cdot 10^{6} \mathrm{~m}^{-1}$. Figure 2 shows variation of the parameters $P_{0}$ и $T_{0}$ measured in the second prechamber during a run of the wind tunnel. It 


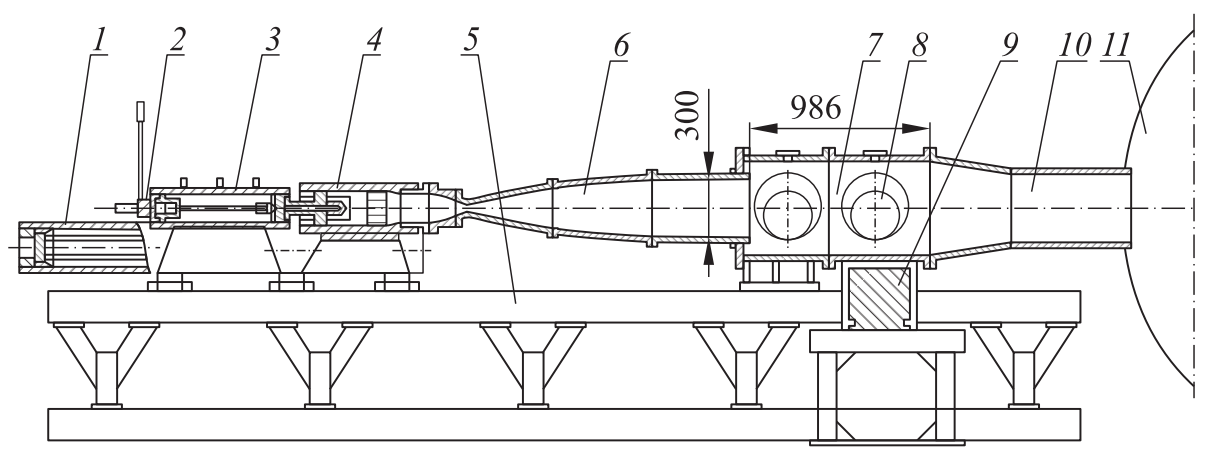

Figure 1 Wind tunnel "Tranzit-M:" 1 - ohmic heater; 2 - high-speed valve; $3-$ first prechamber; 4 - second prechamber; $5-$ frame; $6-$ contoured nozzle; $7-$ test section; 8 - optical windows; 9 - isolated model base; 10 - diffuser; and 11 vacuum tank. Dimensions are in millimeters

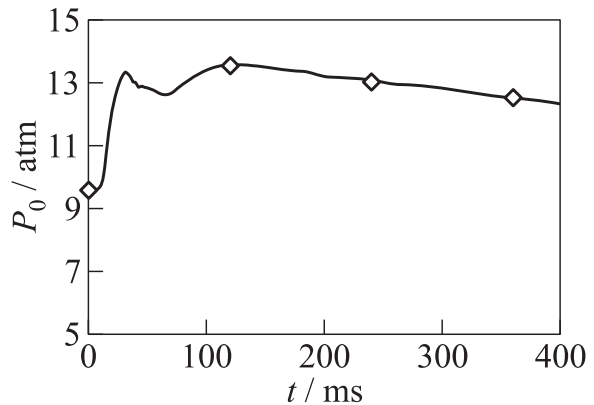

(a)

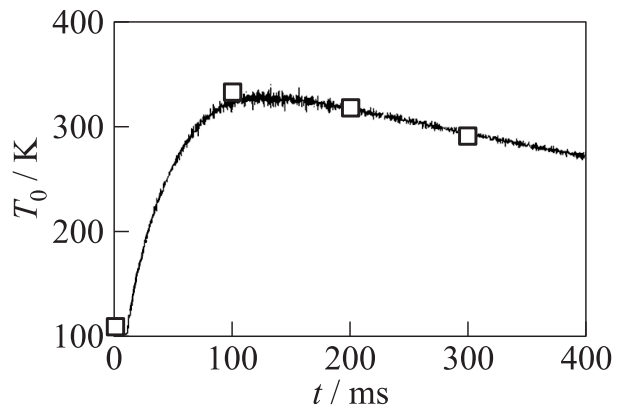

(b)

Figure 2 Stagnation pressure $(a)$ and temperature $(b)$ of the flow during a run

can be seen that after the opening of the fast valve, there is a graduate change of stagnation parameters. For each run, the data analysis was performed for a time window where $\operatorname{Re}_{1}$ change was within $5 \%$. The corresponding time window is shown in Fig. 2. The duration of the window was varied from 90 to $200 \mathrm{~ms}$ depending on the initial flow parameters. To obtain $P_{0}$ and $T_{0}$, the pressure and temperature data were averaged within the window.

Investigation of free stream noise of the tunnel showed that the noise level was about $3 \%$ [15]. The information on free stream noise spectra was used for normalization of calculated spectra (see section 3 ).

The experimental model was a 7 degree half-angle sharp nosed cone. The drafts of the model are presented in Figs. 3 and 4. The model is assembled from 4 sections including the interchangeable cooler and heater sections. The 


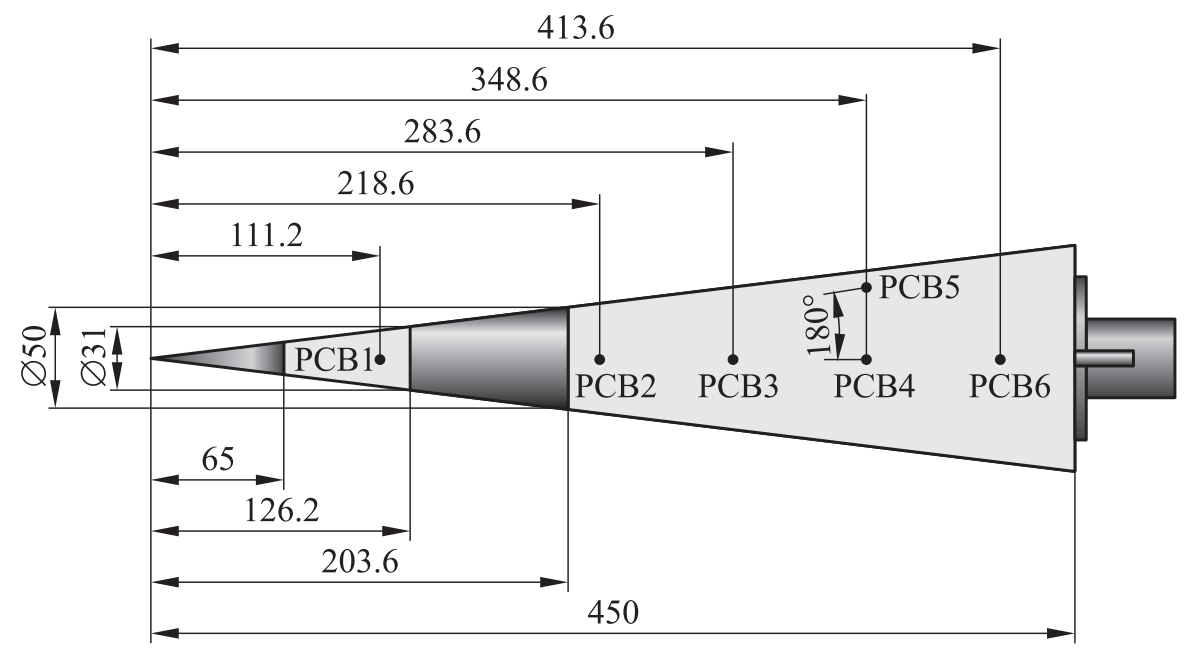

Figure 3 Draft of the 7 degree cone model and positions of pressure sensors. Dimensions are in millimeters

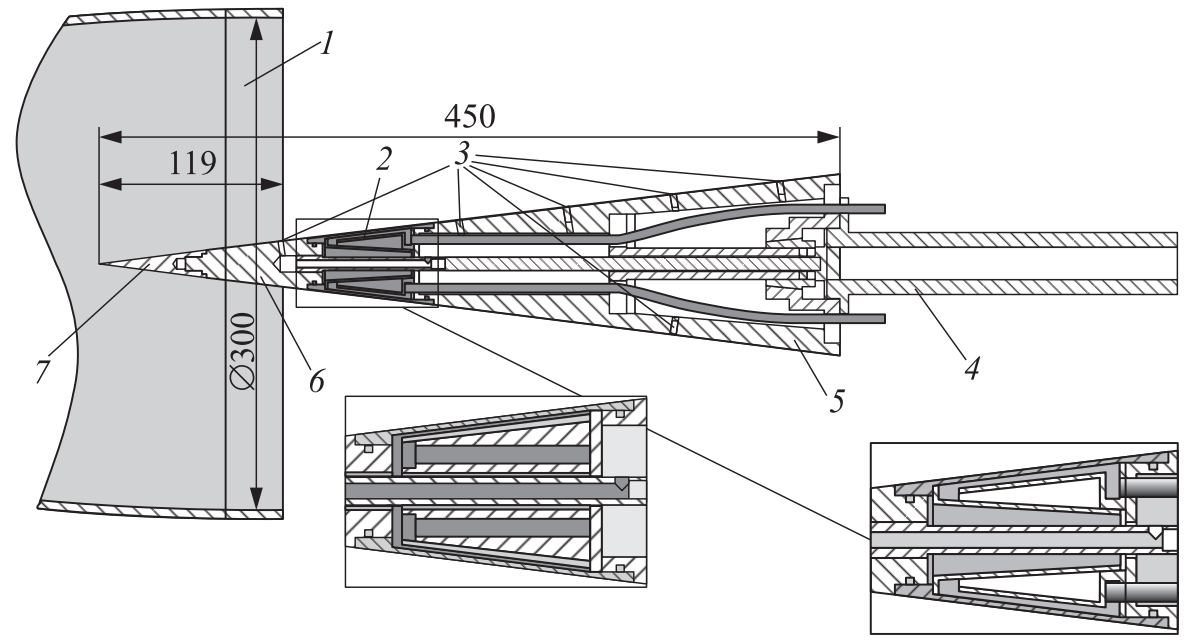

Figure 4 Draft of the model with heater/cooler sections: 1 - wind tunnel nozzle; 2 - heater/cooler section; 3 - PCB sensor; 4 - model support; 5 - flare section; 6 - middle section; and 7 - nose section. Dimensions are in millimeters 
cooler is made of copper and utilize liquid nitrogen flow to control the temperature. The heater has the same cowl; ceramic insert with ohmic heater is used for heating. Typical time of operation to achieve the maximum/minimum temperature is about 120-200 s. The main part of the model body is made of PEEK (polyetheretherketone) to prevent heat diffusion. The maximum temperature of the heater was dictated by PEEK properties and limited by $T_{w}=440 \mathrm{~K}$. Minimum temperature of the cooler was close to boiling point of liquid nitrogen $\left(T_{w}=90 \mathrm{~K}\right)$. The model is equipped by pressure sensors PCB $132 \mathrm{~A} 31$ to measure pulsations of a surface pressure. Positions of the sensors are indicated in Fig. 4. The spectra obtained by PCB 4 and PCB 5 were used to set zero angle of attack and sideslip of the model.

Pressure sensors were used with a signal converter PCB Piezotronocs 482 S05. The data were recorded by means of ADC (analog-to-digital converter) L-card E20-10 with sampling frequency $2 \mathrm{MHz}$. Intrinsic noise of pressure sensors was measured before each experiment and taken into account in processing the data.

Spectral analysis of the pressure pulsation was performed by the discrete Fourier transform. Spectral distributions were calculated by averaging over $L$ blocks on $2^{n}$ samples in each block. Usually, the number of blocks was varied from 428 to 858 , with the number of samples in the block 1024 and 512, respectively. The spectra obtained were used for calculation of the mean-square level of fluctuations in a given frequency band.

Additionally to pressure pulsation measurements, the transition location was investigated by infrared (IR) technique. Camera SVIT (Semiconductor Vision Infrared Thermograph) was used to measure distribution of temperature on the model surface during a run. The heat flux distributions were obtained from the surface temperature using assumption of semiinfinite body. Schlieren visualization was performed to detect density gradients in the flow near the cooler/heater and to obtain intermittency level in the transitional boundary layer. High-speed camera Phantom $310 \mathrm{~m}$ was used with frame rate $8.6 \mathrm{kHz}$.

\subsection{Experimental Results}

Before each run, the model was under room conditions $(T=290 \mathrm{~K})$ and the temperature distribution was uniform everywhere. After vacuumization of the test chamber, the desired temperature of the cooler/heater $T_{w}$ was achieved and the flow was started immediately after that. Due to relatively short time of $T_{w}$ establishment and low heat conductivity of PEEK, the region of the heat penetration was short enough. The wall temperature distributions measured right before the run of the wind tunnel are presented in Fig. 5.

The experimental results are presented below as the summarized data for the both cases of heating and cooling. The experiments were performed for Reynolds number from $4.2 \cdot 10^{6}$ to $20 \cdot 10^{6} \mathrm{~m}^{-1}$ and each run was repeated twice. 


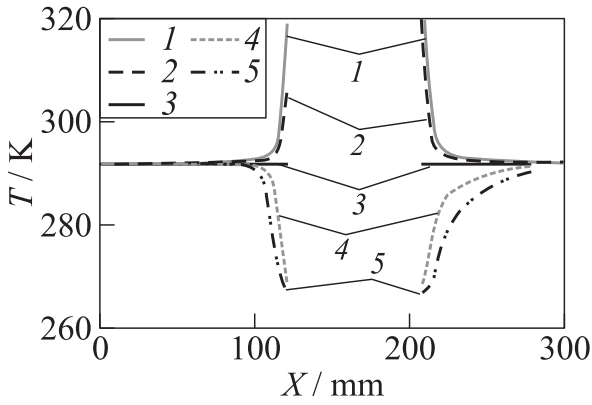

Figure 5 Wall temperature distributions just before the run for various $T_{w}: 1-443 \mathrm{~K}$; $2-373 ; 3-292 ; 4-157$; and $5-90 \mathrm{~K}$

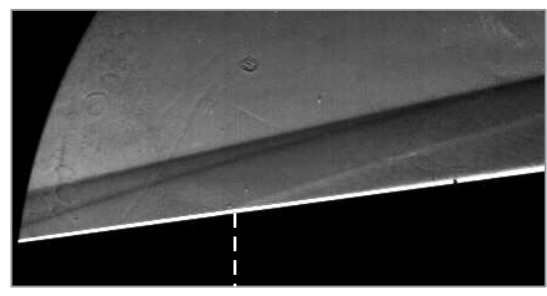

$x=203.6 \mathrm{~mm}$

(a)
Schlieren visualization was performed to study the flow in vicinity of the cooler/heater and to detect the turbulent spots in transitional boundary layer. The averaged schlieren images of the flow above the heated and cooled surface elements are presented in Fig. 6. The knife edge orientation was horizontal in these experiments; so, one can see the corresponding density gradients. The shock wave is followed by expansion waves in the case of heater. The flow pattern is reversed in the case of cooler.

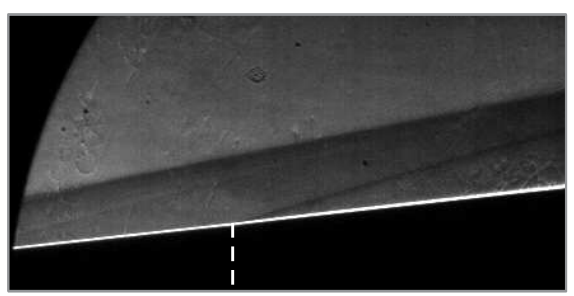

$$
x=203.6 \mathrm{~mm}
$$

(b)

Figure 6 Schlieren visualization of the flow near the heater/cooler section (flow from the left to the right): $(a)$ heating $\left(T_{w}=440 \mathrm{~K}\right)$; and $(b)$ cooling $\left(T_{w}=90 \mathrm{~K}\right)$. The end of heater/cooler is shown by the dashed line

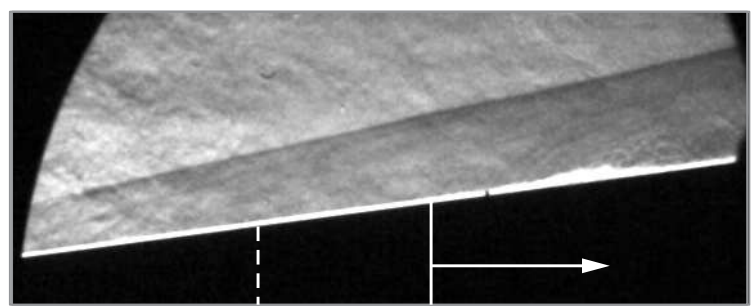

$$
x=203.6 \mathrm{~mm}_{x}=247 \mathrm{~mm}
$$

Figure 7 Turbulent spot on the schlieren visualization. The end of heater/cooler is shown by the dashed line 

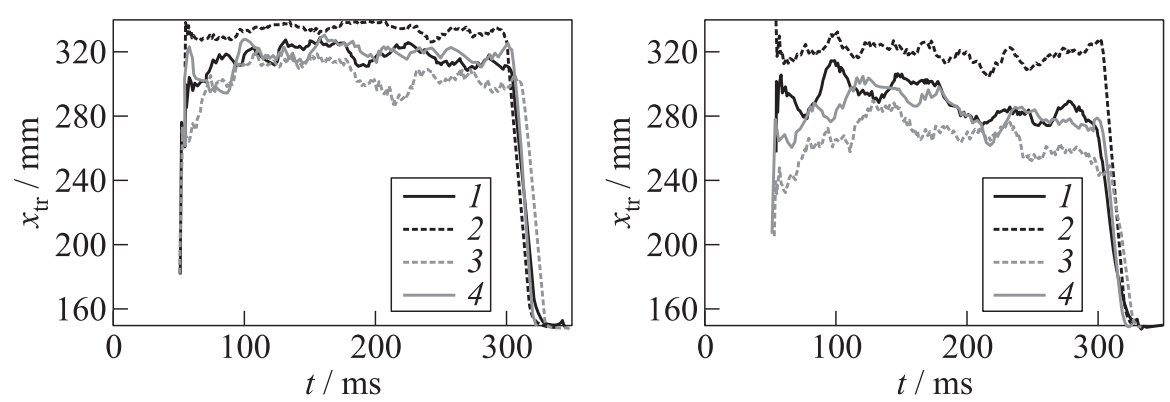

(a)
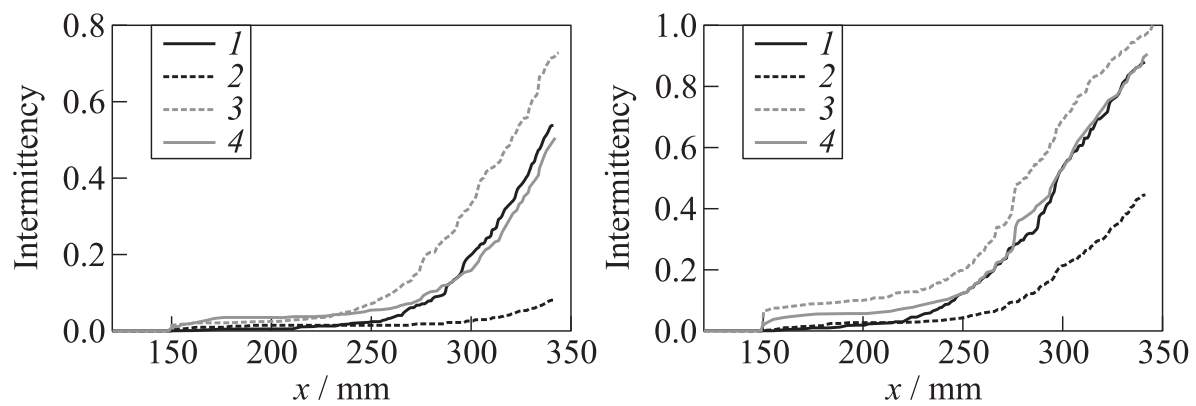

(b)

Figure 8 Transition beginning position obtained from schlieren visualization $(a)$ and intermittency in the translational boundary layer $(b): 1-$ reference $\left(T_{w}=290 \mathrm{~K}\right)$ assembly for cooling; 2 - cooling $\left(T_{w}=90 \mathrm{~K}\right) ; 3$ - heating $\left(T_{w}=440 \mathrm{~K}\right)$; and $4-$ reference $\left(T_{w}=290 \mathrm{~K}\right)$ assembly for heating. Left column refers to $\operatorname{Re}_{1}=16.5 \cdot 10^{6} \mathrm{~m}^{-1}$ and right column refers to $\mathrm{Re}_{1}=20 \cdot 10^{6} \mathrm{~m}^{-1}$

Turbulent spots were detected in the instantaneous schlieren images as zones of the boundary layer inflation (Fig. 7). The positions of the inflation beginning $x_{\text {tr }}$ were defined for each frame and are presented in Fig. $8 a$. The curves in the figures present filtered data to reveal the general trend: running average filter was applied using a window size of 150 points. It can be seen that heating effectively shifts transition beginning upstream and cooling shifts it downstream.

Intermittency levels based on schlieren visualization are presented in Fig. $8 b$. It is necessary to take into account that the intermittency at definite position $x$ is defined as ratio of number of frames where the transition was detected upstream of this $x$ to the total number of frames. It can be seen that the surface cooling intensively delays the transition. The effect of the heating is opposite and less pronounced.

Heat flux distributions were measured by IR camera for various Re and temperature factors of the surface section. 
To calculate heat fluxes along the model, the temperature distribution in time was smoothed. Cook-Felderman algorithm [16] was applied to numerically integrate the solution of equations of heat propagation in semiinfinite plate. The data are summarized in Figs. 9-13 as streamwise distributions of Stanton number. The data are presented for the region downstream of the heater/cooler. The Stanton number was calculated as

$$
\mathrm{St}=\frac{Q}{\operatorname{Re}_{1 e} \mu_{e} C_{p}\left(T_{0}-T_{\text {surf }}\right)}
$$

where $Q$ is the measured value of the heat flux. Estimated Stanton number calculation error is about $15 \%$.

It can be seen from the Fig. 9 that for low Re, the boundary layer is mostly laminar and the heat flux is nearly constant for the reference test case. The curves for heated and cooled surface element reveal the heat exchange of the surface with the boundary layer heated or cooled upstream. The heat accumulated in bounadary layer during its passage above the heater increases the heat flux to the model body downstream. The heat flux downstream of the cooler is accordingly lower than the reference values. This effect is evident in Figs. 9-13.

It is commonly accepted that maximum of the heat flux (or Stanton number) is associated with the end of transition and increasing of the heat flux corresponds to transitional boundary layer. This maximum may be found for the first time in the case of heating for $\operatorname{Re}_{1}=8.3 \cdot 10^{6} \mathrm{~m}^{-1}$. At the same time there is no evident maximum for the reference and cooling cases at this Reynolds number. Increasing of Re results in movement transition location upstream and transition end may be clearly seen in Figs. 9-14.

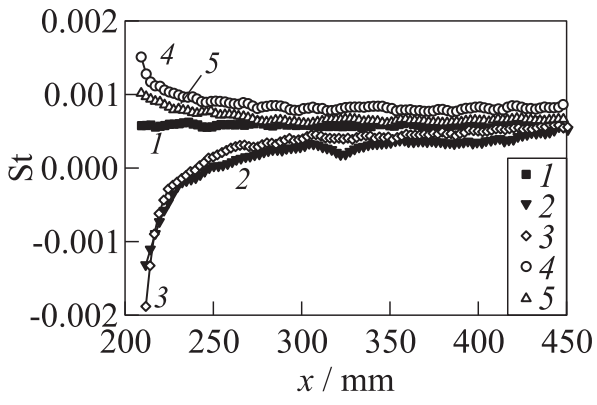

Figure 9 Distributions of Stanton number on the cone surface for $\mathrm{Re}_{1}=4.4$ $\times 10^{6} \mathrm{~m}^{-1}: 1-T_{w} / T_{r}=0.94 ; 2-$ $0.29 ; 3-0.51 ; 4-1.40 ;$ and $5-$ $T_{w} / T_{r}=1.21$

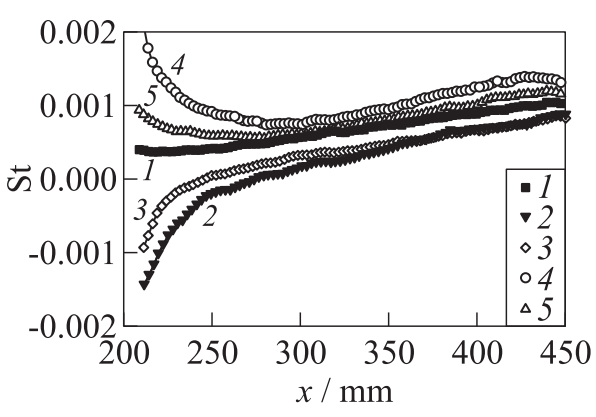

Figure 10 Distributions of Stanton number on the cone surface for $\mathrm{Re}_{1}=8.6$ $\times 10^{6} \mathrm{~m}^{-1}: 1-T_{w} / T_{r}=0.95 ; 2-$ $0.30 ; 3-0.47 ; 4-1.46 ;$ and $5-$ $T_{w} / T_{r}=1.24$ 


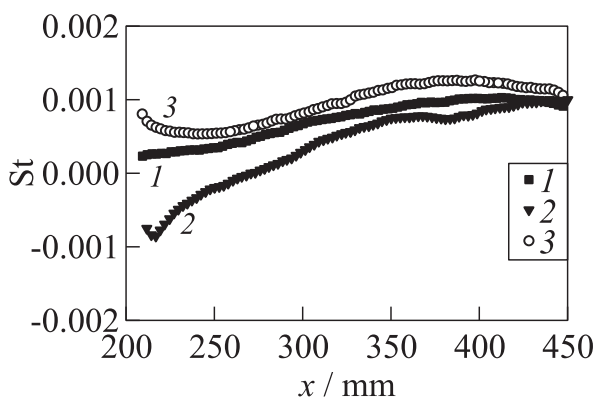

Figure 11 Distributions of Stanton number on the cone surface for $\mathrm{Re}_{1}=13$ $\times 10^{6} \mathrm{~m}^{-1}: 1-T_{w} / T_{r}=0.95 ; 2-0.30$; and $3-T_{w} / T_{r}=1.46$

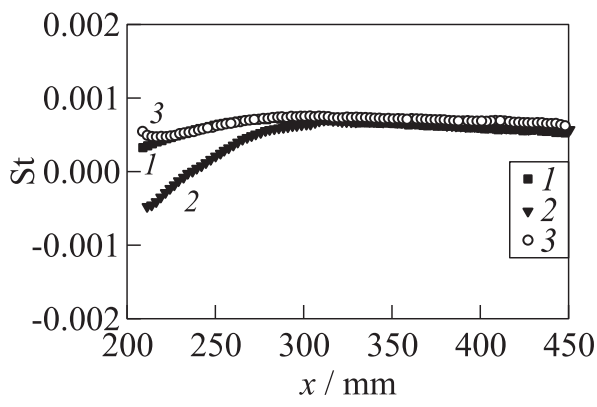

Figure 13 Distributions of Stanton number on the cone surface for $\mathrm{Re}_{1}=20.5$ $\times 10^{6} \mathrm{~m}^{-1}: 1-T_{w} / T_{r}=0.94 ; 2-0.29$; and $3-T_{w} / T_{r}=1.39$

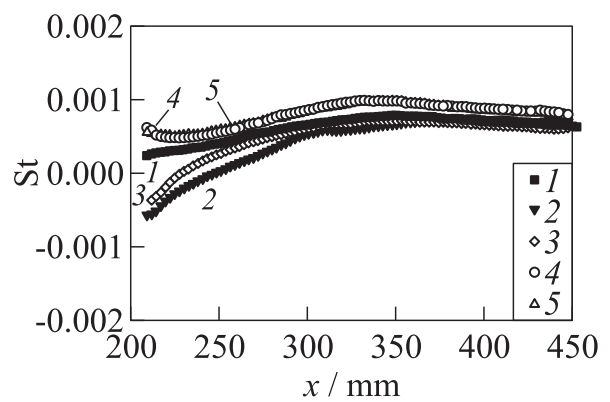

Figure 12 Distributions of Stanton number on the cone surface for $\mathrm{Re}_{1}=17$ $\times 10^{6} \mathrm{~m}^{-1}: 1-T_{w} / T_{r}=0.93 ; 2-$ $0.29 ; 3-0.50 ; 4-1.41 ;$ and $5-$ $T_{w} / T_{r}=1.21$

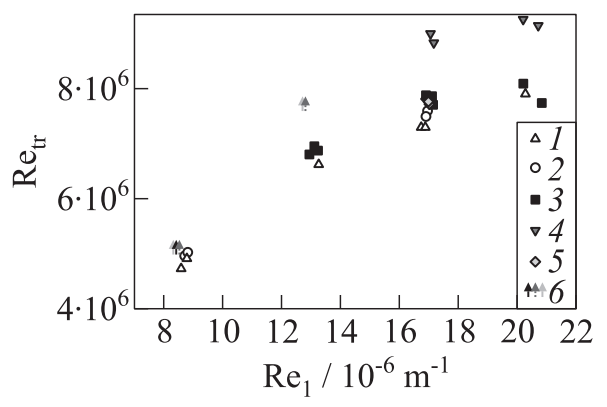

Figure 14 Position of the transition end: $1-T_{w} / T_{r}=1.4 ; 2-1.2 ; 3-$ $0.95 ; 4-0.30 ;$ and $5-T_{w} / T_{r}=0.5$; and 6 - no transition

The general effect of local surface temperature change is shown in Figs. 9-13. Cooling of the surface effectively shifts the transition location downstream and the magnitude of the effect size depends on temperature factor $T_{w} / T_{r}$. Heating of the surface results in transition displacement upstream and this effect is less pronounced. It should be taken into account that maximum heating of the surface allowed to increase the surface temperature by $47 \%$ whereas cooling decreases the temperature to about $70 \%$. The positions of transition end obtained from the heat flux distributions are summarized in Fig. 14.

Surface pressure pulsations were measured by means of 6 sensors. Five of them were placed in-line and used to study development of the disturbances in the boundary layer. Positions of the sensors are indicated in Fig. 3. An example 


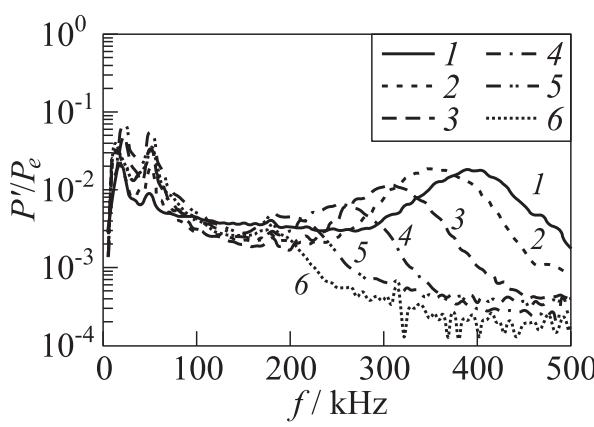

(a)

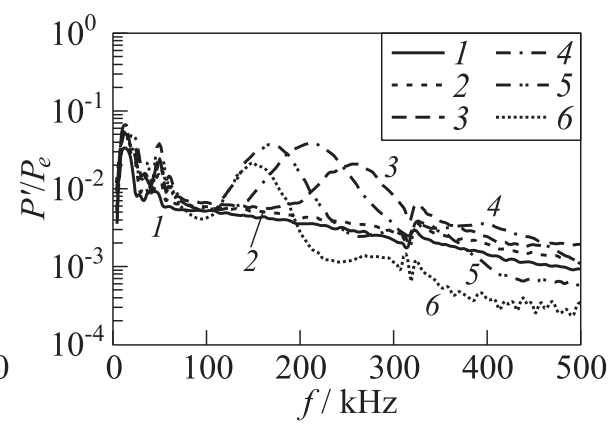

(b)

Figure 15 Variation of pressure pulsation spectra for PCB $2(a)$ and PCB $4(b)$ and various $T_{w} / T_{r}$ and Reynolds numbers: $1-T_{w} / T_{r}=0.95, \mathrm{Re}_{1}=19.8 \cdot 10^{6} \mathrm{~m}^{-1} ; 2-$ $T_{w} / T_{r}=0.94, \mathrm{Re}_{1}=16.6 \cdot 10^{6} \mathrm{~m}^{-1} ; 3-T_{w} / T_{r}=0.94, \mathrm{Re}_{1}=12.5 \cdot 10^{6} \mathrm{~m}^{-1} ; 4-$ $T_{w} / T_{r}=0.95, \operatorname{Re}_{1}=8.36 \cdot 10^{6} \mathrm{~m}^{-1} ; 5-T_{w} / T_{r}=0.95, \operatorname{Re}_{1}=5.46 \cdot 10^{6} \mathrm{~m}^{-1} ;$ and $6-T_{w} / T_{r}=0.94, \operatorname{Re}_{1}=4.25 \cdot 10^{6} \mathrm{~m}^{-1}$

of the obtained data is presented in Figs. 15-23. Figures 15-17 demonstrate variation of spectra for two stations and various $T_{w} / T_{r}$ and Reynolds numbers. Figures 18-23 show comparison of pulsation spectra for various $T_{w} / T_{r}$ at the same location. The data are presented as amplitude spectra of the pressure pulsations $P^{\prime}$ normalized by mean surface pressure $P_{e}$.

The evolution of the second mode with growth of $\operatorname{Re}_{1}$ may be clearly seen in Fig. 15a. At the station of PCB 2, the second mode amplitude is rising with increasing $\operatorname{Re}_{1}$ and its frequency becomes higher due to decreasing of boundary layer thickness. At the downstream position of PCB 4 (see Fig. 15b), the gradual amplification of the second mode with $\mathrm{Re}_{1}$ growth is broken by beginning of turbulization at $\operatorname{Re}_{1}=8.36 \cdot 10^{6} \mathrm{~m}^{-1}$. The spectra for higher $\mathrm{Re}_{1}$ demonstrate decreasing of the second mode and filling of the spectra.

Cooling of the surface results in damping of the second mode and delay of its amplification as shown in Figs. $16 a$ and 16b. Amplitude of the second mode detected by PCB 2 is much lower here. The transition at Fig. $16 b$ is also shifted to higher $\mathrm{Re}_{1}$ in comparison with the reference case (see Fig. 15b).

Effect of the surface heating is shown in Figs. $17 a$ and $17 b$ for PCB 2 and PCB 4, correspondingly. Figures $17 a$ and $17 b$ show that pulsation amplitudes of the second mode are lower than the corresponding reference values. Lowfrequency waves growing in Fig. $17 a$ shows that beginning of transition has occurred at PCB 2 for high $\mathrm{Re}_{1}$. Analysis of Fig. $17 b$ reveals the end of transition at PCB 4 at $\operatorname{Re}_{1}=16.6 \cdot 10^{6} \mathrm{~m}^{-1}$.

Dependance of the pressure pulsation spectra on $T_{w} / T_{r}$ for single sensor may be found in Figs. 18-23. It can be seen that the surface temperature affects 


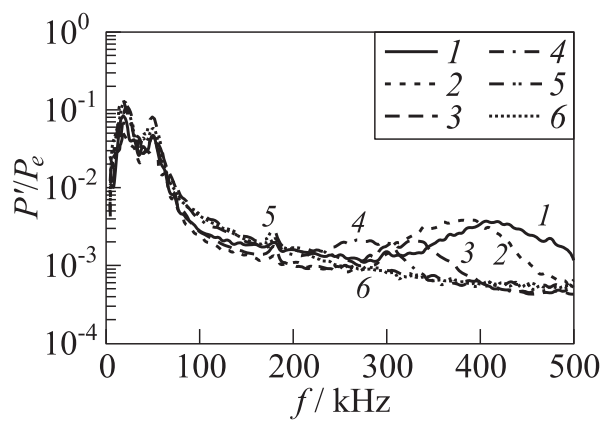

(a)

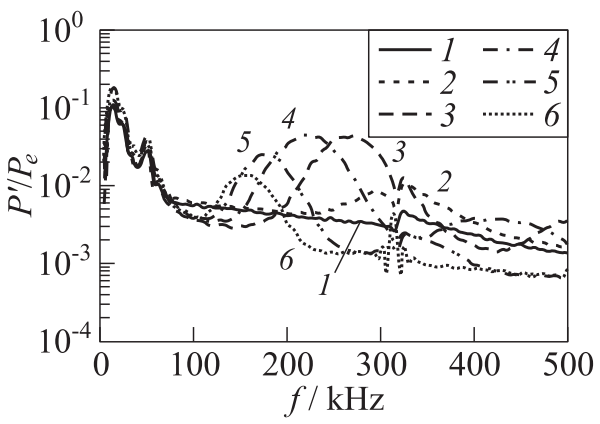

(b)

Figure 16 Variation of pressure pulsation spectra for PCB $2(a)$ and PCB $4(b)$ and various $T_{w} / T_{r}$ and Reynolds numbers: $1-T_{w} / T_{r}=0.29, \mathrm{Re}_{1}=19.7 \cdot 10^{6} \mathrm{~m}^{-1} ; 2-$ $T_{w} / T_{r}=0.29, \mathrm{Re}_{1}=16.7 \cdot 10^{6} \mathrm{~m}^{-1} ; 3-T_{w} / T_{r}=0.30, \mathrm{Re}_{1}=12.7 \cdot 10^{6} \mathrm{~m}^{-1} ; 4-$ $T_{w} / T_{r}=0.28, \operatorname{Re}_{1}=8.28 \cdot 10^{6} \mathrm{~m}^{-1} ; 5-T_{w} / T_{r}=0.30, \mathrm{Re}_{1}=5.46 \cdot 10^{6} \mathrm{~m}^{-1} ;$ and $6-T_{w} / T_{r}=0.29, \operatorname{Re}_{1}=4.26 \cdot 10^{6} \mathrm{~m}^{-1}$

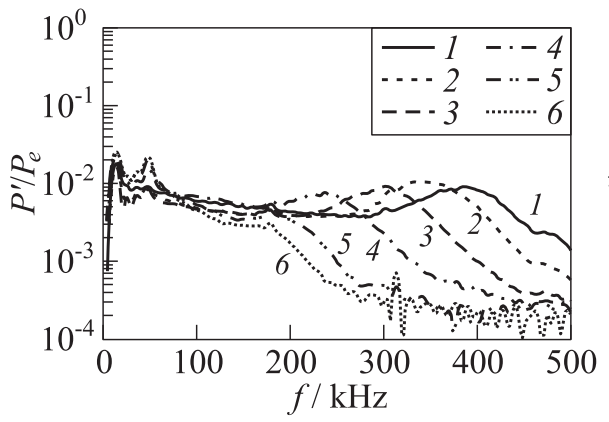

(a)

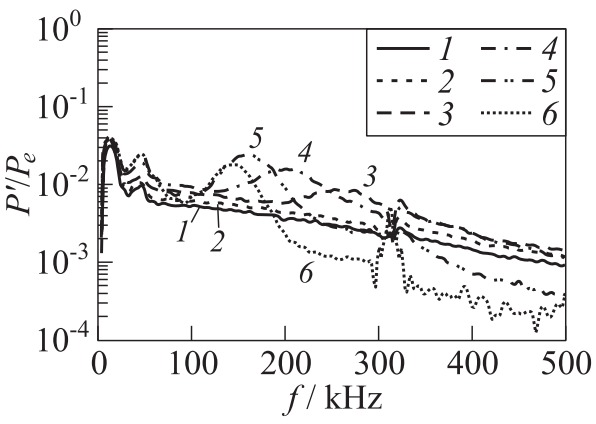

(b)

Figure 17 Variation of pressure pulsation spectra forfor PCB $2(a)$ and PCB $4(b)$ and various $T_{w} / T_{r}$ and Reynolds numbers: $1-T_{w} / T_{r}=1.39, \mathrm{Re}_{1}=19.8 \cdot 10^{6} \mathrm{~m}^{-1}$; $2-T_{w} / T_{r}=1.42, \mathrm{Re}_{1}=16.4 \cdot 10^{6} \mathrm{~m}^{-1} ; 3-T_{w} / T_{r}=1.46, \mathrm{Re}_{1}=12.8 \cdot 10^{6} \mathrm{~m}^{-1}$; $4-T_{w} / T_{r}=1.43, \operatorname{Re}_{1}=8.27 \cdot 10^{6} \mathrm{~m}^{-1} ; 5-T_{w} / T_{r}=1.39, \mathrm{Re}_{1}=5.17 \cdot 10^{6} \mathrm{~m}^{-1}$; and $6-T_{w} / T_{r}=1.41, \operatorname{Re}_{1}=4.23 \cdot 10^{6} \mathrm{~m}^{-1}$

the peak frequency of the second mode due to the effect of the boundary layer thickness. The spectra corresponding to low $\mathrm{Re}_{1}$ (see Figs. 18 and 19) show that cooling decreases amplitude of the second mode in laminar boundary layer. It is necessary to mention that second mode peak for the test case of heating is also decreased. It can be explained by beginning of nonlinear evolution of the second mode and dissipation of energy of pulsations. Increasing of the pulsation amplitude in range $80-120 \mathrm{kHz}$ supports this supposition. It can be found that the 


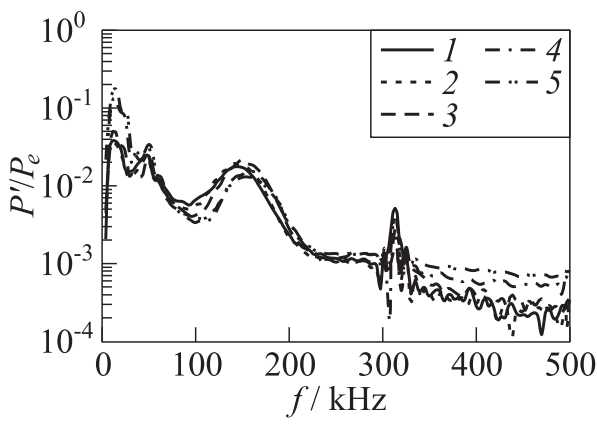

Figure 18 Comparison of the pressure pulsation spectra for various $T_{w} / T_{r}$ and $\mathrm{Re}_{1}$ at $\mathrm{PCB}$ 4: $1-T_{w} / T_{r}=1.41, \mathrm{Re}_{1}$ $=4.23 \cdot 10^{6} \mathrm{~m}^{-1} ; 2-T_{w} / T_{r}=1.21$, $\operatorname{Re}_{1}=4.22 \cdot 10^{6} \mathrm{~m}^{-1} ; 3-T_{w} / T_{r}=0.94$, $\mathrm{Re}_{1}=4.25 \cdot 10^{6} \mathrm{~m}^{-1} ; 4-T_{w} / T_{r}=0.50$, $\operatorname{Re}_{1}=4.22 \cdot 10^{6} \mathrm{~m}^{-1} ;$ and $5-T_{w} / T_{r}$ $=0.29, \operatorname{Re}_{1}=4.26 \cdot 10^{6} \mathrm{~m}^{-1}$

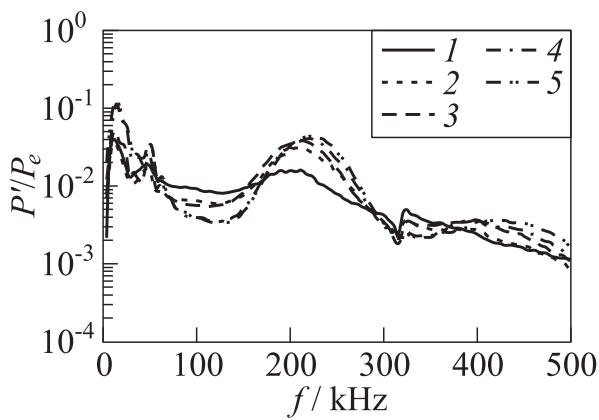

Figure 20 Comparison of the pressure pulsation spectra for various $T_{w} / T_{r}$ and $\mathrm{Re}_{1}$ at $\mathrm{PCB} 4: 1-T_{w} / T_{r}=1.43, \mathrm{Re}_{1}$ $=8.27 \cdot 10^{6} \mathrm{~m}^{-1} ; 2-T_{w} / T_{r}=1.24$, $\mathrm{Re}_{1}=8.45 \cdot 10^{6} \mathrm{~m}^{-1} ; 3-T_{w} / T_{r}=0.95$, $\operatorname{Re}_{1}=8.36 \cdot 10^{6} \mathrm{~m}^{-1} ; 4-T_{w} / T_{r}=0.47$, $\mathrm{Re}_{1}=8.23 \cdot 10^{6} \mathrm{~m}^{-1} ;$ and $5-T_{w} / T_{r}$ $=0.28, \operatorname{Re}_{1}=8.28 \cdot 10^{6} \mathrm{~m}^{-1}$

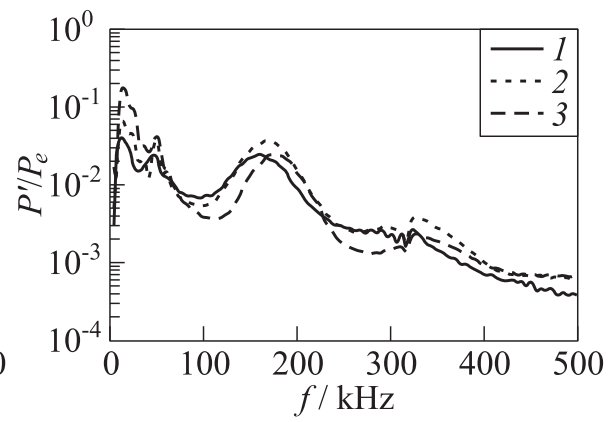

Figure 19 Comparison of the pressure pulsation spectra for various $T_{w} / T_{r}$ and $\mathrm{Re}_{1}$ at $\mathrm{PCB} 4: 1-T_{w} / T_{r}=1.39, \mathrm{Re}_{1}$ $=5.17 \cdot 10^{6} \mathrm{~m}^{-1} ; 2-T_{w} / T_{r}=0.95$, $\operatorname{Re}_{1}=5.46 \cdot 10^{6} \mathrm{~m}^{-1} ;$ and $3-T_{w} / T_{r}$ $=0.30, \operatorname{Re}_{1}=5.46 \cdot 10^{6} \mathrm{~m}^{-1}$

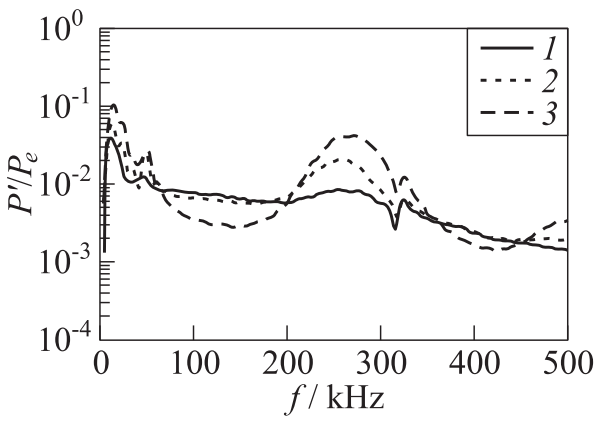

Figure 21 Comparison of the pressure pulsation spectra for various $T_{w} / T_{r}$ and $\operatorname{Re}_{1}$ at $\mathrm{PCB} 4: 1-T_{w} / T_{r}=1.46, \mathrm{Re}_{1}$ $=12.8 \cdot 10^{6} \mathrm{~m}^{-1} ; 2-T_{w} / T_{r}=0.94$, $\operatorname{Re}_{1}=12.5 \cdot 10^{6} \mathrm{~m}^{-1}$; and $3-T_{w} / T_{r}$ $=0.30, \operatorname{Re}_{1}=12.7 \cdot 10^{6} \mathrm{~m}^{-1}$

nonlinear stage (see Figs. 20 and 21) comes earlier for higher temperature factor with gradual increase of Reynolds number, resulting in dissipation of the second mode (amplitude fall) and filling of the spectra at low frequency range. Transition is delayed for the lowest temperature factor as seen in Fig. 22: the amplitude 


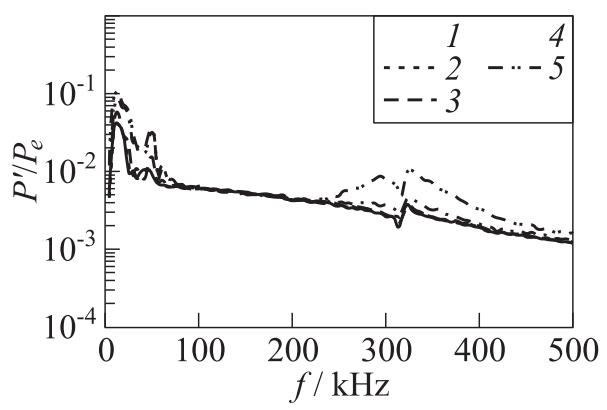

Figure 22 Comparison of the pressure pulsation spectra for various $T_{w} / T_{r}$ and $\operatorname{Re}_{1}$ at PCB 4: $1-T_{w} / T_{r}=1.42, \operatorname{Re}_{1}$ $=16.4 \cdot 10^{6} \mathrm{~m}^{-1} ; 2-T_{w} / T_{r}=1.21$, $\operatorname{Re}_{1}=16.5 \cdot 10^{6} \mathrm{~m}^{-1} ; 3-T_{w} / T_{r}=0.94$, $\operatorname{Re}_{1}=16.6 \cdot 10^{6} \mathrm{~m}^{-1} ; 4-T_{w} / T_{r}=0.52$, $\mathrm{Re}_{1}=16.5 \cdot 10^{6} \mathrm{~m}^{-1} ;$ and $5-T_{w} / T_{r}$ $=0.29, \operatorname{Re}_{1}=16.7 \cdot 10^{6} \mathrm{~m}^{-1}$

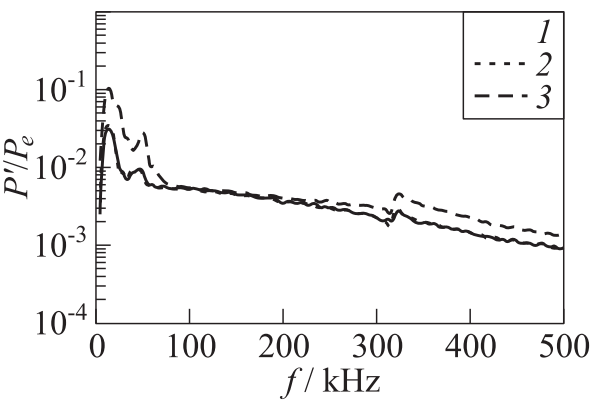

Figure 23 Comparison of the pressure pulsation spectra for various $T_{w} / T_{r}$ and $\mathrm{Re}_{1}$ at $\mathrm{PCB} 4: 1-T_{w} / T_{r}=1.39, \mathrm{Re}_{1}$ $=19.8 \cdot 10^{6} \mathrm{~m}^{-1} ; 2-T_{w} / T_{r}=0.95$, $\operatorname{Re}_{1}=19.8 \cdot 10^{6} \mathrm{~m}^{-1} ;$ and $3-T_{w} / T_{r}$ $=0.29, \operatorname{Re}_{1}=19.7 \cdot 10^{6} \mathrm{~m}^{-1}$

of the second mode is still distinguished. The spectra presented here reveal that the boundary layer is completely turbulent for all temperature factors except $T_{w} / T_{r}=0.29$ where one can see the late stage of transition. So, it is seen that local temperature jump influences the boundary layer up to the late stage of transition. Figure 23 shows completely turbulent boundary layer for all test cases.

\section{NUMERICAL SIMULATION}

The numerical simulation was performed for preliminary estimation of the experimental conditions and posterior analysis of the experimental data. Reliable modeling of laminar/turbulent transition is possible only by direct numerical simulation and involves considerable computational power; therefore, it cannot be used for the parametrical study. To simplify computations, the current simulation deals only with linear stage of the disturbance development. The boundary layer stability was numerically studied in two-dimensional (2D) assumption to simulate only development of the most unstable $2 \mathrm{D}$ waves of the second mode.

The numerical simulation was performed only for $\operatorname{Re}_{1}=5.75 \cdot 10^{6} \mathrm{~m}^{-1}$. Commercial computational fluid dynamics (CFD) software Fluent/ANSYS was used for simulation of axisymmetrical flow on the cone. Quadrilateral grid of $271 \times 7500$ cells was used for computations. The boundary layer conditions on the wall corresponded to the experimental ones. Three test cases were considered corresponding to reference conditions $\left(T_{w}=293 \mathrm{~K}\right)$, local wall heating 


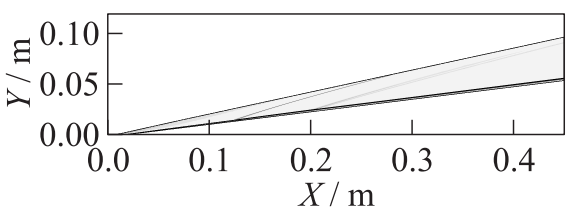

(a)

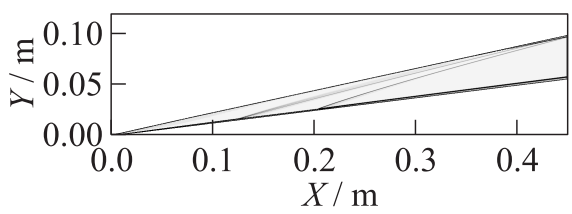

(b)

Figure 24 Spatial gradient of density: (a) $T_{w} / T_{r}=1.42$; and $(b) T_{w} / T_{r}=0.26$

$\left(T_{w}=450 \mathrm{~K}\right)$, and cooling $\left(T_{w}=90 \mathrm{~K}\right)$. The temperature of the rest of the wall was $293 \mathrm{~K}$. The gradient of the wall temperature on the cooler/heater border in simulation was sharper in comparison with the experiment. The special computation was done to study the effect of the wall temperature gradient on the disturbance development. It was found that small length of the heat penetration obtained in the experiment do not influence the disturbance development. The CFD density gradients corresponding to the heated and cooled wall section are presented in Fig. 24.

Generation of disturbances in CFD simulation was carried out by means of small synthetic jet on the model surface located at $x=7 \mathrm{~mm}$. Sequential analysis of many frequencies is not efficient because the growth of perturbations occurs in a wide range of frequencies and separate review of a large number of discrete frequencies requires a substantial amount of computation time. Therefore, it was decided to use linear combination of several harmonic waves of equal amplitude in frequency range $75<f<425 \mathrm{kHz}$ as the initial perturbation. An example of resulting synthetic disturbance is shown in Fig. 25 where 18 waves are linearly combined. The preliminary calculations had shown a good agreement between the level of perturbation obtained in batch mode and reconstructed as sum of the individual frequencies. The disturbance spectra obtained in CFD simulation were normalized by spectrum of free flow pulsations obtained in the experiment (presented in Fig. 26) to take into account spectral content of the wind tunnel noise.

The distributions of mean surface pressure and instantaneous pressure pulsations are shown in Figs. 27 and 28. It is seen that the surface pressure gradients are higher in the case of cooling due to big change in temperature factor in this case $\left(T_{w} / T_{r}=1.42\right.$ for heating and $T_{w} / T_{r}=0.26$ for cooling). The influence of surface cooling on disturbance amplitude is very powerful but local as shown in Figs. 27 and 28. Downstream of the cooler, the wave packet weakens and undergoes gradual growth further downstream. It has to be taken into account that the synthetic jet excites in the boundary layer a complex wave structure consisting of combination of many waves. Therefore, the instantaneous pressure distributions reveal the beating as shown in Fig. $27 b$.

The streamwise distributions of the pressure pulsation amplitude of the separated waves obtained by spectral analysis of the wave packet are presented in 


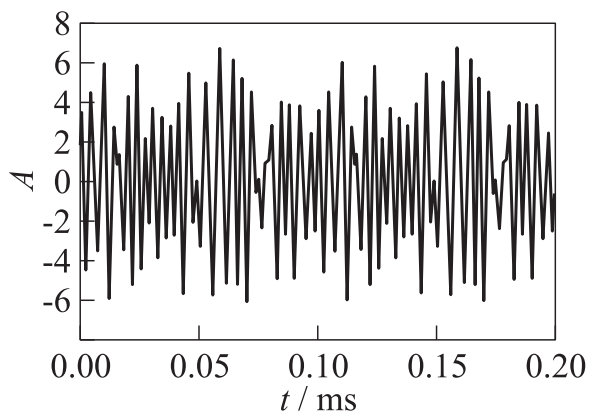

Figure 25 Iinitial synthetic disturbance

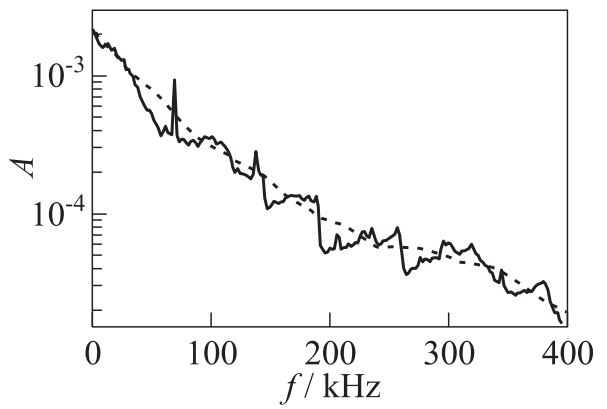

Figure 26 Amplitude of wind tunnel noise; dashed curve — smoothed spectrum

Fig. 28. It is seen that behavior of the waves strongly depends on their frequency. In comparison to the reference case, the wave of the second mode of frequency $f=150 \mathrm{kHz}$ experiences higher amplification downstream of the heated surface section. The same wave behind the cooled wall section undergoes some delay of amplification (Fig. 28a). There is no evident effect on this wave over the cooler/heater. In all test cases, the wave is gradually amplified up to the right border of the calculation area.

The wave of frequency $170 \mathrm{kHz}$ demonstrates the same behavior downstream the heater/cooler (Fig. 28b). Due to higher frequency, this wave undergoes maximum amplification within the computational domain and begins to decay at $x=0.37 \mathrm{~m}$ for the reference case. In the case of heating, the wave reaches its maximum faster and maximum amplitude is lower than in the reference case. Because second mode growth strongly depends on the boundary layer thickness and its growth, the decrease of boundary layer thickness by cooling results in delay of the wave evolution. More detailed explanation of this phenomenon is given below.

The wave of frequency $210 \mathrm{kHz}$ undergoes amplification and decay within the computation domain for all test cases (Fig. 28c). The resulting maximum amplitudes for all cases are much lower. The effect of local wall heating and cooling here is also associated with the change of the boundary layer thickness and the most pronounced downstream of the heater/cooler section. This wave begins to amplify during its passage over the heater. Some rise of the amplitude can be found at the heater end.

The wave of the highest frequency presented here corresponds to $f=260 \mathrm{kHz}$. Its behavior can be found in Fig. 28d. This wave undergoes amplification upstream of the heater/cooler section. Upstream of the section, the curves for all test cases coincide. The most evident effect presented in Fig. 28d in strong 


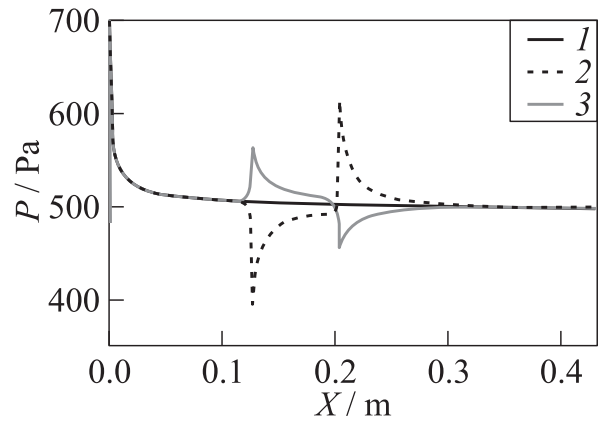

(a)

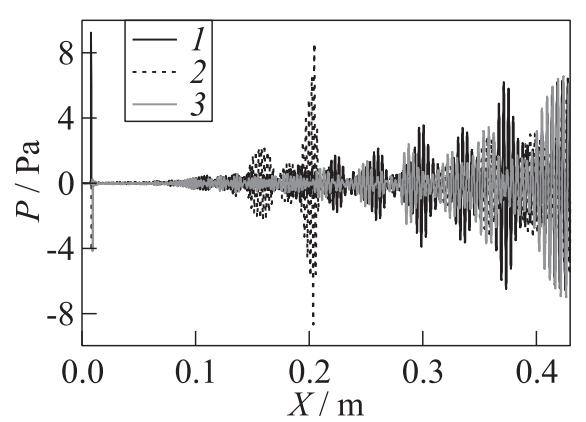

(b)

Figure 27 Mean surface pressure distribution $(a)$ and instantaneous value of surface pressure pulsations $(b): 1-$ reference $\left(T_{w}=293 \mathrm{~K}\right) ; 2-$ cooling $\left(T_{w}=90 \mathrm{~K}\right)$; and 3 - heating $\left(T_{w}=450 \mathrm{~K}\right)$

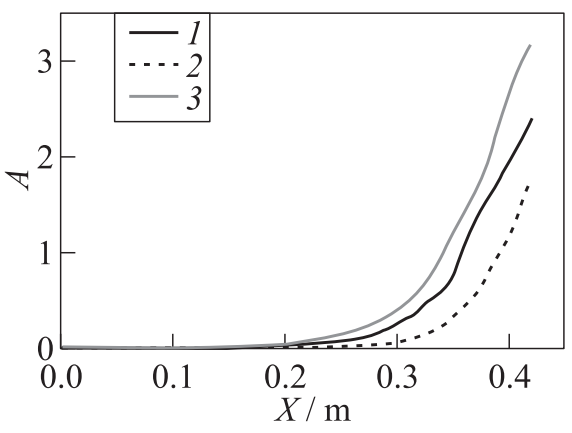

(a)

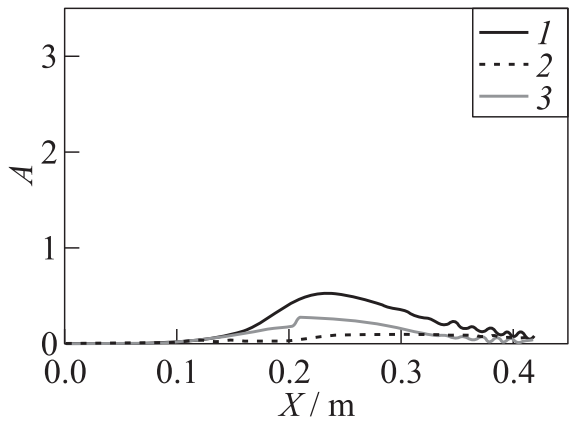

(c)

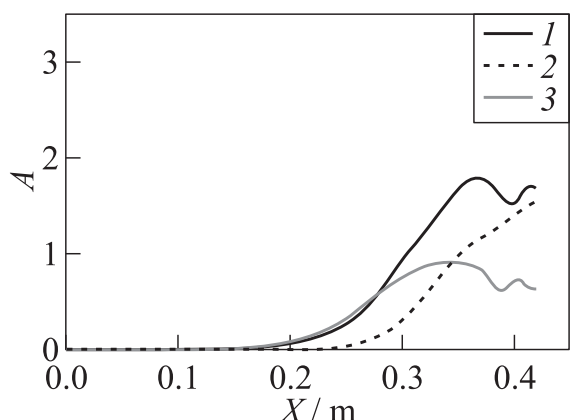

(b)

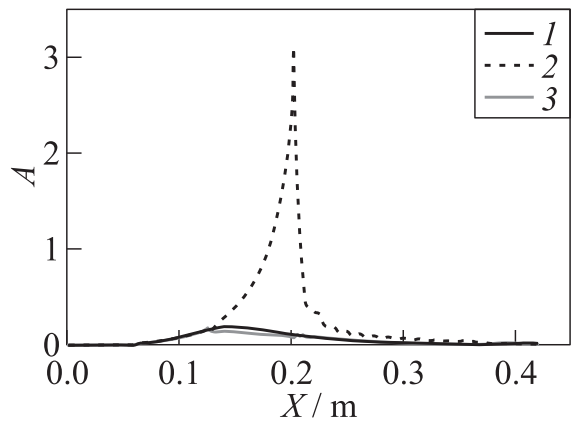

(d)

Figure 28 Streamwise distributions of amplitudes of isolated waves: $(a) f=150 \mathrm{kHz}$; (b) $170 ;(c) 210$; and $(d) f=260 \mathrm{kHz} ; 1$ - reference $\left(T_{w}=293 \mathrm{~K}\right) ; 2$ - cooling $\left(T_{w}=90 \mathrm{~K}\right) ;$ and 3 - heating $\left(T_{w}=450 \mathrm{~K}\right)$ 
amplification of the wave over the cooler. Directly downstream of the cold wall section the wave is strongly damped.

So, it is obvious that behavior of waves having different frequencies is different. The behavior of a wave of certain frequency is strongly related with a boundary layer thickness, because wavelength on the second mode waves depends on boundary layer thickness. In the baseline case without heating/cooling of the wall, the unstable disturbances responsible for transition develop in the boundary layer gradually achieving

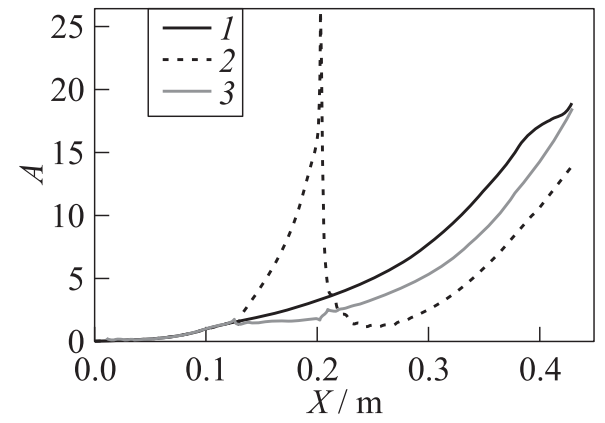

Figure 29 Streamwise distributions of RMS value of pressure pulsations: 1 - reference $\left(T_{w}=293 \mathrm{~K}\right) ; 2-$ cooling $\left(T_{w}\right.$ $=90 \mathrm{~K})$; and 3 - heating $\left(T_{w}=450 \mathrm{~K}\right)$ critical amplitude and initiating turbulence in the flow. The growth rate and frequency of the most unstable waves of the second mode depend mostly on the local thickness of the boundary layer.

In the case of local cooling buildup of the boundary layer, the thickness is reduced in the cooler region, thereby prolonging the favourable conditions for amplification of some high-frequency disturbances. Low temperature of the wall additionally increases their amplification rate. However, due to the small length of the cooling element, these perturbations cannot grow up to a critical amplitude and initiate the transition. Downstream of the region, there is accelerated growth of the boundary layer thickness as a result of flow heating by the relatively warm wall. In this zone, the amplification region (i. e., the region of relatively constant boundary layer thickness) for disturbances of each certain frequency is reduced and perturbations cannot achieve critical amplitude that leads to later turbulence and downstream transition displacement.

In a case of heating, the opposite scenario is occurred. Because of thickening of the boundary layer in the heater zone, the region of disturbance growth for each certain frequency is shortened and perturbations cannot achieve critical amplitude. Downstream of the heater, the rate of boundary layer thickness growth is reduced as a result the relatively cold wall. In this zone, where boundary layer thickness changes slowly, the favorable conditions for the growth of some disturbances of the second mode are established that leads to faster turbulence.

Streamwise distributions of root-mean-square (RMS) value of pressure pulsations are shown in Fig. 29 for all CFD test cases. These values were obtained by recording of the wall pressures during considerable time period and include contribution of all frequencies of the wave packet. It is seen from the figure that a strong local amplification of some frequencies increase RMS value above the cooler. Downstream of the cooler, these waves rapidly decay and do not influ- 


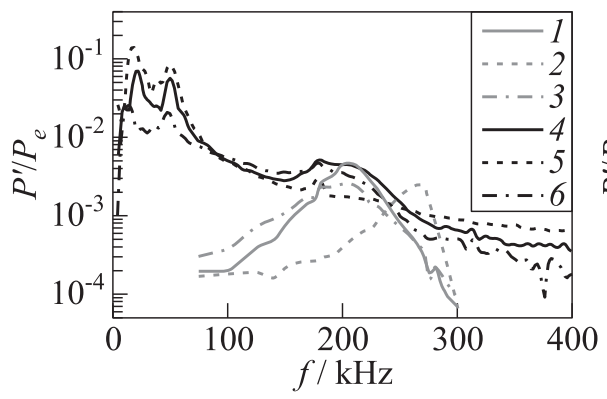

(a)

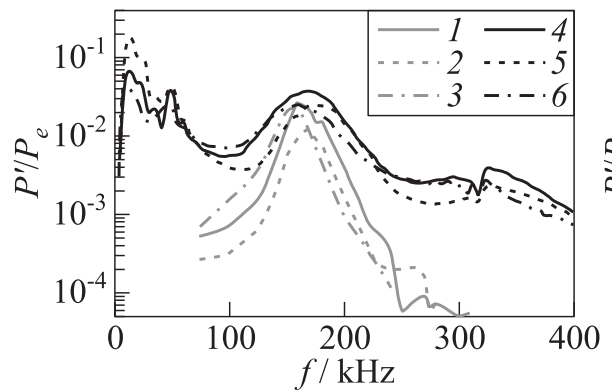

(c)

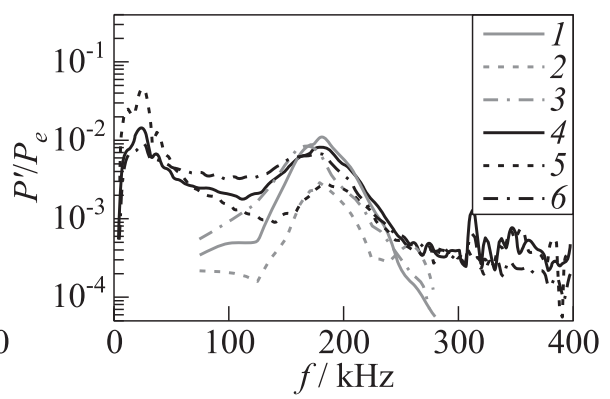

(b)

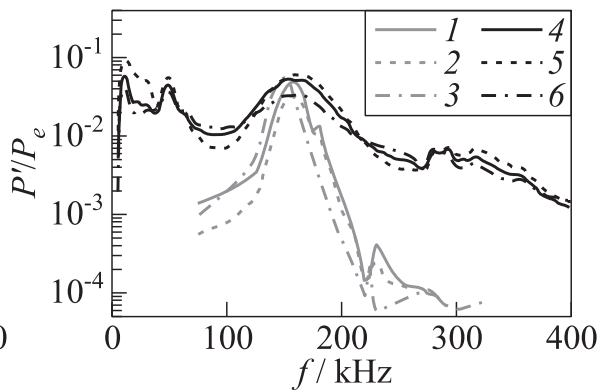

(d)

Figure 30 Comparison of pressure pulsation spectra: (a) $X=219 \mathrm{~mm}$; (b) 284; (c) 349; and $(d) X=414 \mathrm{~mm} ; 1-T_{w}=293 \mathrm{~K}(\mathrm{DNS}) ; 2-90(\mathrm{DNS}) ; 3-450$ (DNS); $4-290 ; 5-90$; and $6-T_{w}=440 \mathrm{~K}$

ence RMS value which is produced mostly by unstable waves of lower frequencies. Their behavior determines the streamwise distribution of the RMS value. It is seen that for cooling and heating of the surface, the RMS values are lower than in the reference case.

Figure 30 shows comparison of the pressure pulsation spectra measured in the experiment for $\mathrm{Re}_{1}=5.75 \cdot 10^{6} \mathrm{~m}^{-1}$ and obtained by CFD. The computational spectra were normalized by smoothed spectrum of free flow pulsations presented in Fig. 26.

The computational data are presented for the same positions as positions of PCB 2, 3, 4 and 6 in the experiment. It is seen from Fig. 30 that there is a good agreement of frequency of the second mode almost everywhere along the model between the computation and the experiment. The agreement of the amplitude is also rather good taking into account experimental accuracy. It can be seen from Fig. $30 b$ that cooling of the surface significantly reduces amplitude of the second mode at $x=284 \mathrm{~mm}$. The amplitude for the case of heating is also less than in the reference case. Further downstream (Fig. 30c), the disturbances of the 
second mode for all cases are amplified and amplification is higher for the case of cooling. Nevertheless, the value of amplitude of the second mode for the case of cooling is lower than for other cases. There is no such a good agreement between calculation and experiment at $x=349 \mathrm{~mm}$ but qualitatively data show the same behavior. Calculated behavior of the second mode at position $x=414 \mathrm{~mm}$ differs from the one obtained in the experiment: in calculation, the second mode in cooling case still has minimum amplitude and in heating case, amplitude is maximum while experiment shows the opposite. The most likely reason for this is the beginning of nonlinear interactions at this position in the experiment.

\section{CONCLUDING REMARKS}

The experimental study of local surface temperature effect on the hypersonic boundary layer stability and transition was performed for $\mathrm{M}=6$ in wind tunnel "Tranzit-M." The transition location was obtained by several techniques. Evolution of the disturbances in the boundary layer was studied based on surface pressure pulsation measurements. The experiments were performed in a range of temperature factor $0.3<T_{w} / T_{r}<1.4$ for a wide range of Reynolds numbers.

It was obtained that the local surface temperature has strong effect on the boundary layer stability and transition. The experiments revealed that heating of the surface section accelerates the transition downstream of the section. Cooling of the surface element significantly delays the transition. This behavior is completely different from the known effect of uniform heating of surface that stabilizes the second mode and of uniform cooling that destabilizes the second mode.

Development of the disturbances in the boundary layer was studied by means of the wall pressure pulsations measurement. It was obtained that wall temperature significantly affects the evolution of the second mode. In contrast to temperaure change of the whole model, local heating/cooling of surface affects in different ways on the waves with different frequencies. But in general, the second mode is damped by local wall cooling for low Reynolds numbers. This effect is opposite to the influence caused by cooling of the whole model. It is well known that cooling increases amplification rates of the second mode. Due to extended region of the boundary layer transition, the results obtained for higher Re are more complex and difficult to analize. Nevertheless, heat flux measurements clearly showed that integral effect presented: the transition was shifted downstream by means of local cooling; local heating, in contrary, shifted transition upstream in comparison to reference case.

The numerical simulation was performed to study evolution of the wave packet in the boundary layer for experimental flow conditions. The numerical simulation demonstrates very good agreement with the experimental data in terms of all details of the second mode development. 


\section{ACKNOWLEDGMENTS}

The study was supported by EU in framework of TransHyBeriAN FP7 project and RFBR (grant 15-01-04788).

\section{REFERENCES}

1. Mack, L. M. 1984. Boundary-layer linear stability theory. AGARD Report 7091984 (Special course on stability and transition of laminar flows).

2. Malik, M. R. 1989. Prediction and control of transition in supersonic and hypersonic boundary layers. AIAA J. 27(11):1487-1493.

3. Malik, M. R., T. A. Zang, and D. M. Bushnell. 1990. Boundary layer transition in hypersonic flows. AIAA Paper No. 90-5232.

4. Stetson, K. F., and R. L. Kimmel. 1992. On hypersonic boundary-layer transition. AIAA Paper No. 92-0737.

5. Schneider, S. P. 2004. Hypersonic laminar-turbulent transition on circular cones and scramjet forebodies. Prog. Aerosp. Sci. 40(1-2):1-50.

6. Maslov, A. A., A. N. Shipyluk, D. A. Bountin, and A. A. Sidorenko. 2006. Mach 6 boundary-layer stability experiments on sharp and blunt cones. J. Spacecraft Rockets $43(1): 71-76$.

7. Maslov, A. A., A. V. Fedorov, D.A. Bountin, A. N. Shiplyuk, A. A. Sidorenko, N. D. Malmuth, and H. Knauss. 2008. Experimental study of disturbances in transitional and turbulent hypersonic boundary layers. AIAA J. 46(7):1880-1883.

8. Rushton, G.H., and K.F. Stetson. 1967. Shock tunnel investigation of boundarylayer transition at $\mathrm{M}=5.5$. AIAA J. 5(5):899-905. doi:10.2514/3.4098.

9. Demetriades, A. 1978. New experiments on hypersonic boundary layer stability including wall temperature effect. Proc. Heat Tran. Fluid Mech. Inst. 39-54.

10. Stetson, K. F., E. R. Thompson, J. C. Donaldson, and L. G. Siler. 1989. Laminar boundary layer stability experiments on a cone at Mach 8. Part 5: Tests with a cooled model. AIAA Paper No. 89-1895.

11. Mack, L. M. 1990. On the inviscid acoustic-mode instability of supersonic shear flows. Theor. Comp. Fluid Dyn. 2:97-123.

12. Kara K., P. Balakumar, and O. Kandil. 2008. Effects of wall cooling on hypersonic boundary layer receptivity over a cone. 38th Fluid Dynamics Conference and Exhibit. 10.2514/6.2008-3734.

13. Soudakov, V., A. Fedorov, and I. Egorov. 2013. Investigations of laminar-turbulent transition on a sharp cone with localized heating or cooling in high-speed flow. 51st AIAA Aerospace Sciences Meeting including the New Horizons Forum and Aerospace Exposition. 10.2514/6.2013-524

14. Zvegintsev, V.I. 1992. Impulse aerodynamic wind tunnel with electric heater. Conference (International) on the Methods of Aerophysical Research Proceedings. Novosibirsk, Russia: ITAM SB RAS. 2:171-173.

15. Gromyko, Yu. V., V. A. Polivanov A. A. Sidorenko, D. A. Buntin. and A. A. Maslov. 2013. An experimental study of the natural noise in the Transit-M hypersonic wind tunnel. Thermophys. Aeromech. 20(4):481-493.

16. Cook, W.J., and E. J. Felderman. 1966. Reduction of data from thin film heat transfer gauges. A concise numerical technique. AIAA J. 4(3):561. 